\title{
Experimental studies of compliance of vertical joints used in construction of high-rise panel buildings
}

\author{
Aleksandr Shuvalov ${ }^{1}$, Igor Gorbunov ${ }^{1}$, Mikhail Kovalev ${ }^{1}$, and Adelia Faizova ${ }^{1, *}$ \\ ${ }^{1}$ Moscow State University of Civil Engineering, Yaroslavskoe shosse, 26, Moscow, 129337, Russia
}

\begin{abstract}
The results of the experimental studies of the vertical joint compliance used in the construction of the high-rise panel buildings are presented in this article. The vertical joints with various concrete grades, thickness of the panels, number and mutual bracing of the mating elements were used in this research conducted for LLC «LSR» in MGSU. The compliance ratios were measured on three steps: from the beginning of loading till the crack formation in one of the elements - I1; from the beginning of loading till maximal load - I2; from crack formation till maximal load - I3. Gained values can be used as basic data for structural engineering of panel high-rise buildings.
\end{abstract}

\section{Introduction}

In the calculations of the high-rise panel buildings, the strength and deformation characteristics corresponding to the structural solutions of the mating elements of the bearing structures should be given as the initial data. In particular, for the projected vertical panel interface nodes, the information is needed on the relative panel displacements as a function of the load on vertical joints of different designs. It is important to obtain a characteristic of the vertical joint compliance in the entire loading range up to the limiting value of shear forces. To date, foreign and domestic scientists have conducted studies of the work of vertical joints with different design solutions. At the same time, the types of the loading and some details of the joint design varied. In work [1] the results of the study of the tensile strength and shear joint based on the use of thread connection were obtained. The digging of M16x50 anchor bolt with depth of $50 \mathrm{~mm}$ and BT- Spannschloss lock (Germany), occurs at loadings of $\sim 50 \mathrm{kN}$. When tested in shear panels connected by two tie locks BT- Spannschloss depending on the embodiment of the vertical joint (10-20 mm) execution the significant differences of the limit values detected in the shear force and rigidity connections $[270 \div 140] \mathrm{kN} ;[2.5 \div 30.1] \mathrm{kN} / \mathrm{mm}$, which does not reliably recommend the calculated values of rigidity and ultimate force. In the work [2] the vertical joint of panels of type LS [3], working on shear, with flexible loops and embedding the joint with P-400 grout the solution was investigated [3]. The results are obtained that are of practical interest in assigning initial and calculated rigidity, the calculated shear forces at

\footnotetext{
Corresponding author: 23adelia@gmail.com
} 
the joints. It is not entirely clear what is the actual prismatic strength $\mathrm{Rb}_{\mathrm{b}}=14.1 \mathrm{MPa}$ and what is the reason for the discrepancy $\mathrm{R}_{\mathrm{b}}$ av the $\mathrm{B} 22.5$ concrete class.

\section{Methods}

In the studies conducted at NRU MGSU on the instructions of LLC "LSR", the vertical joints were considered with the structural differences in the thickness of the panels, the number, mutual arrangement of the mating elements and different concrete classes (Table $1)$.

Table 1. Element combinations of vertical joints

\begin{tabular}{|c|c|c|c|}
\hline Sample marking & $\begin{array}{c}\text { Wall panel } \\
\text { thickness, } \mathrm{mm}\end{array}$ & $\begin{array}{c}\text { Concrete wall } \\
\text { panel class }\end{array}$ & $\begin{array}{c}\text { Number of elements } \\
\text { and form of joint }\end{array}$ \\
\hline $\mathrm{C} 1$ & 160 & 15 & \multirow{3}{*}{$\begin{array}{l}\text { T-shaped joint of } 2 \\
\text { elements }\end{array}$} \\
\hline $\mathrm{C} 2$ & 160 & 22.5 & \\
\hline $\mathrm{C} 3$ & 200 & 30 & \\
\hline $\mathrm{C} 4$ & 160 & 15 & \multirow{3}{*}{$\begin{array}{l}\text { L-shaped joint of } 2 \\
\text { elements }\end{array}$} \\
\hline $\mathrm{C} 5$ & 160 & 22.5 & \\
\hline C6 & 200 & 30 & \\
\hline $\mathrm{C} 7$ & 160 & 15 & \multirow{2}{*}{$\begin{array}{c}\text { T-shaped joint of } 3 \\
\text { elements }\end{array}$} \\
\hline $\mathrm{C} 8$ & 200 & 30 & \\
\hline
\end{tabular}

When mounting the vertical joints, the following changes are made to the joint structure:

- The shape (and, correspondingly, the extent) of the weld connecting the embedded parts of the wall panels and the mounting (connecting) angle is changed. The L-shaped seam instead of U-shaped is used;

- In the test samples, the joint was not filled with a grout.

The remaining solutions in the mounting of the joint are taken in accordance with the standard solutions:

- connecting element: unequal angle $125 \times 80 \times 10 \mathrm{~mm}$ according to GOST 8510 ;

- welding: manual with the E46 electrodes, weld leg $\mathrm{K} \mathrm{f}=6 \mathrm{~mm}$.

The tests of vertical joints were carried out on the test-bed consisting of a power frame, rigging and two coupled hydraulic cylinders (Figure 1).

Fig. 1. General view of vertical joint during testing

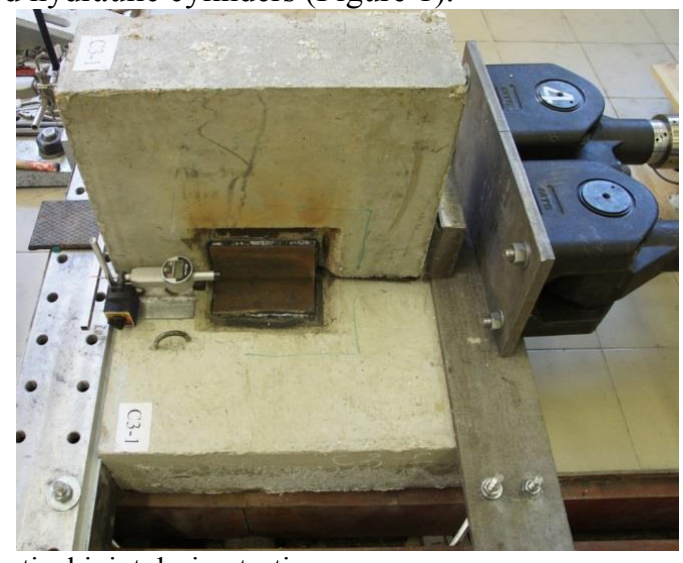


The loading of the joint was carried out in stages, by displacements, taking into account the constructive eccentricity e $=120 \mathrm{~mm}$ (Figure 2 ).

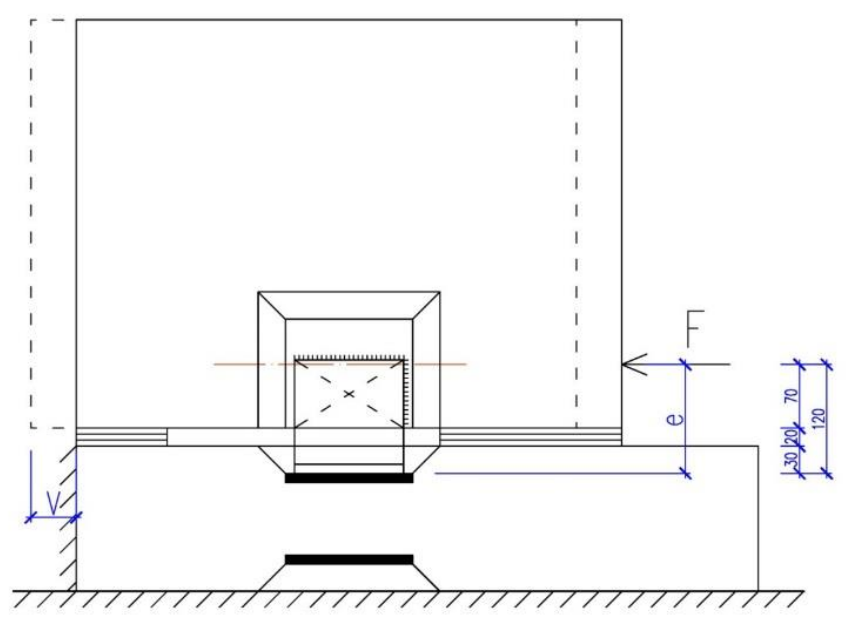

Fig. 2. Load application diagram

To determine the relative displacement of the panels in vertical joints, dial indicators with a $0.01 \mathrm{~mm}$ calibration constant were used. In the T-shaped vertical joint three indicators (two indicators were installed at the level of the force application and one indicator was installed at the end of the movable panel in the region of $50 \mathrm{~mm}$ ) were installed (Figure 3), fixing a possible rotation in the panel plane.

1
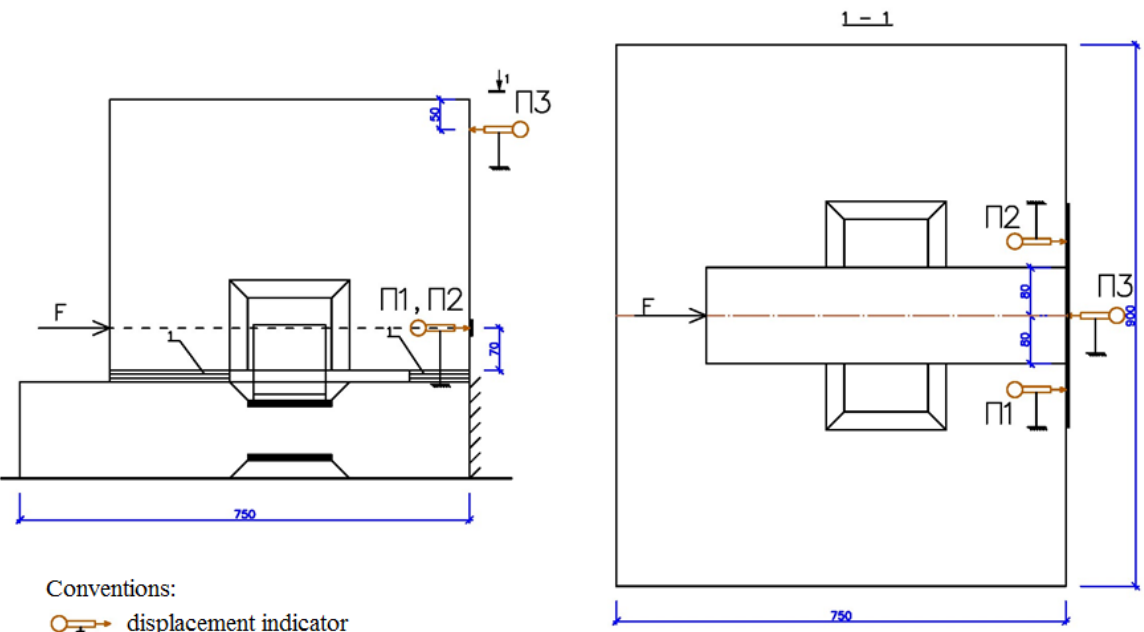

Conventions:

$\mathrm{O} \rightarrow$ displacement indicator

1 - set of steel plates

Fig. 3. Diagram of installation of displacement indicators

For the L-shaped vertical joint, an additional 4th indicator was provided for marking the displacements from the possible rotation from the panel plane. 


\section{Results}

With the eccentricity of load applying e $=120 \mathrm{~mm}, 8$ series of vertical joints $(3$ samples per series) were tested. In Fig. 4-6 the characteristic graphs of the displacement dependence on the joint element load relative to the other for three series of samples differing in the type of joints are shown. The graphs show the relative displacements and loads corresponding to the crack formation in the concrete and the limiting state.

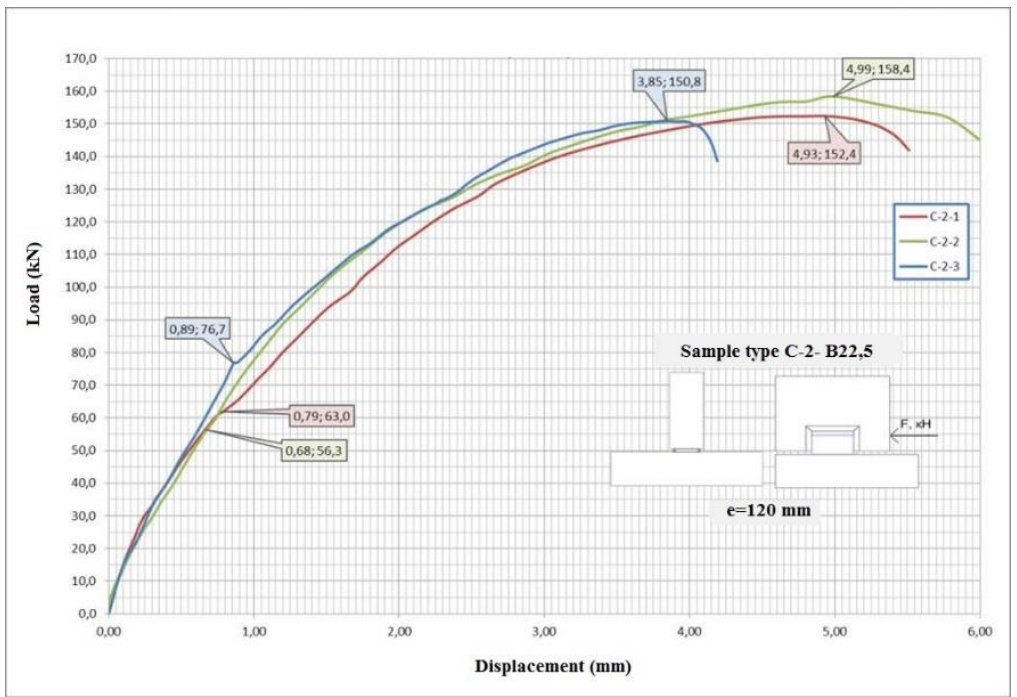

Fig. 4. Dependence "Load - relative displacement of loaded joint element" for C2 samples

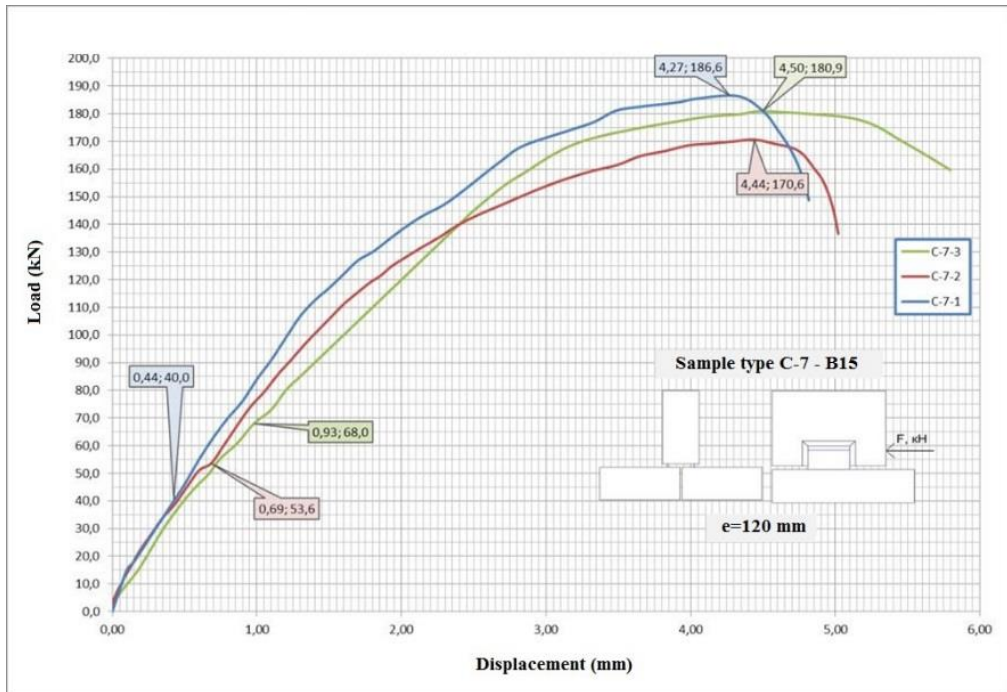

Fig. 5. Dependence "Load - relative displacement of loaded joint element" for C7 samples 


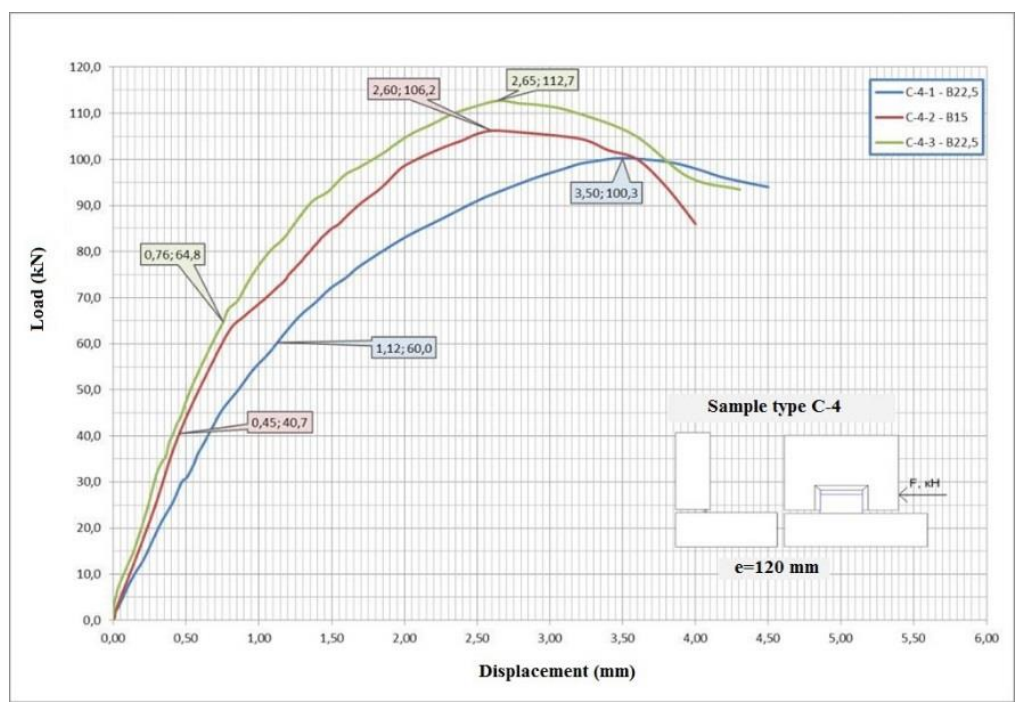

Fig. 6. Dependence "Load - relative displacement of loaded joint element" for C4 samples

The dependence of the compliance ratio, being the derivative of the displacement by the load, is a function that increases nonlinearly. However, from the practical considerations of the calculating of the vertical joints for a specific load, it is possible to estimate the compliance ratios I at three load intervals (Fig. 7):

Until a crack is formed:

$$
\mathrm{I}_{1}=\frac{\mathrm{V}_{t r}}{\mathrm{~F}_{\mathrm{tr}}}
$$

From the beginning of loading to the maximum load:

$$
\mathrm{I}_{2}=\frac{\mathrm{v}_{r}}{\mathrm{~F}_{r}}
$$

From crack formation to maximum load:

$$
\mathrm{I}_{3}=\frac{\mathrm{v}_{r}-\mathrm{v}_{t r}}{\mathrm{~F}_{r}-\mathrm{F}_{t r}}
$$

Where:

$V_{t r}$ - relative displacement in the formation of the first crack in the concrete;

$V_{r}$ - relative displacement at the maximum load; 
$F_{t r}$ - loading of the crack formation;

$F_{r}$ - maximum load.

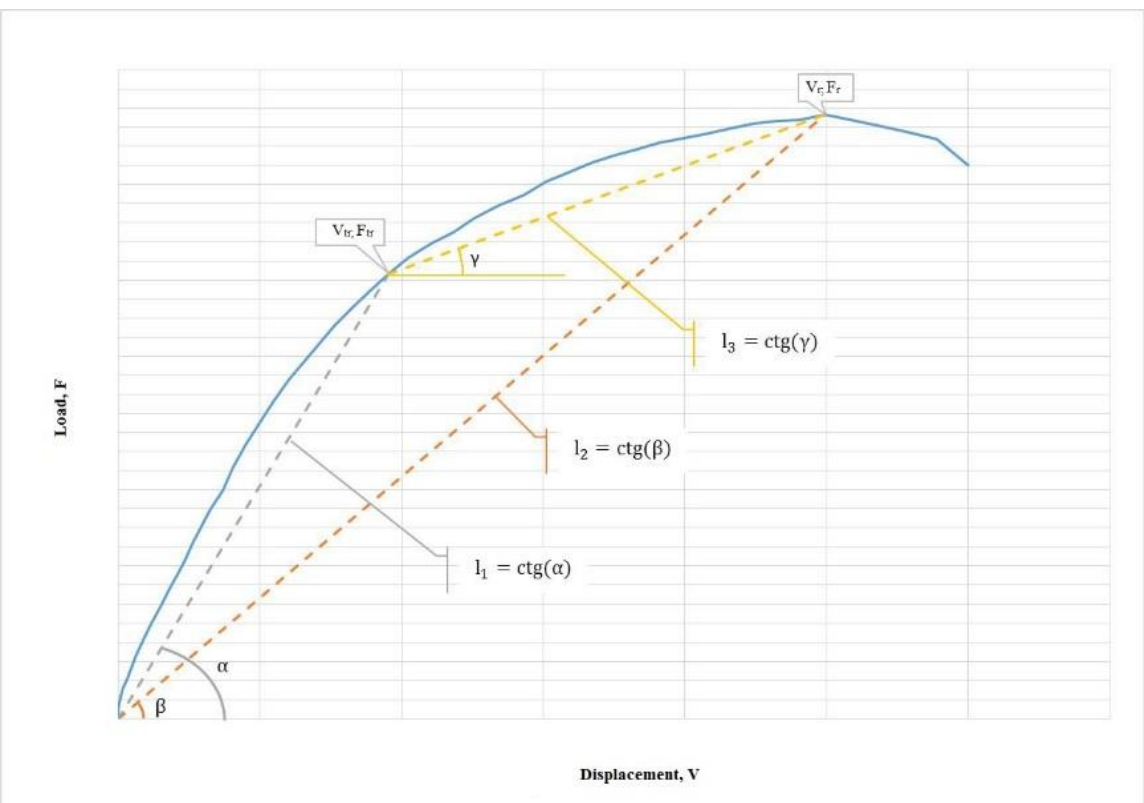

Fig. 7. Compliance ratio determination of vertical joint samples

The values of the compliance ratios (Figure 7) of the mating elements on the linear I1 and non-linear I3 loading regions and over the entire loading range I2 of the vertical joints are presented in Table 2 .

Table 2. Compliance ratios of mating elements of vertical joint samples

\begin{tabular}{|c|c|c|c|c|c|c|}
\hline Number & $I_{1} * 10^{6}$ & $I_{1 \mathrm{cp}} * 10^{6}$ & $I_{2} * 10^{6}$ & $I_{2 a v} * 10^{6}$ & $I_{3} * 10^{6}$ & $I_{3 a v} * 10^{6}$ \\
\hline of joint & $\mathbf{m m} / \mathbf{N}$ & $\mathbf{m m} / \mathbf{N}$ & $\mathrm{mm} / \mathbf{N}$ & $\mathbf{m m} / \mathbf{N}$ & $\mathbf{m m} / \mathbf{N}$ & $\mathbf{m m} / \mathbf{N}$ \\
\hline C1-2 B15 & 14.9 & ---- & 19.6 & ---- & 23.0 & ---- \\
\hline $\begin{array}{c}\mathrm{C} 2-1 \\
\text { B22.5 }\end{array}$ & 12.5 & \multirow{3}{*}{12.1} & 32.3 & \multirow{3}{*}{28.8} & 46.3 & \multirow{3}{*}{43.0} \\
\hline $\begin{array}{c}\mathrm{C} 2-2 \\
\mathrm{~B} 22.5 \\
\end{array}$ & 12.1 & & 31.5 & & 42.2 & \\
\hline $\begin{array}{l}\mathrm{C} 2-3 \\
\mathrm{~B} 22.5\end{array}$ & 11.6 & & 25.5 & & 40.4 & \\
\hline C3-1 B30 & 7.4 & \multirow{3}{*}{7.4} & 14.2 & \multirow{3}{*}{15.6} & 20.0 & \multirow{3}{*}{25.7} \\
\hline C3-2 B30 & 7.1 & & 15.2 & & 23.6 & \\
\hline C3-3 B30 & 7.6 & & 17.4 & & 33.5 & \\
\hline C4-2 B15 & 11.1 & \multirow[b]{2}{*}{11.4} & 24.5 & \multirow[b]{2}{*}{24.0} & 32.8 & \multirow[b]{2}{*}{36.0} \\
\hline $\begin{array}{l}\text { C4-3 } \\
\text { B22.5 }\end{array}$ & 11.7 & & 23.5 & & 39.2 & \\
\hline C5-2 B15 & 21.5 & \multirow[t]{2}{*}{21.8} & \multicolumn{4}{|c|}{$\begin{array}{l}\text { Failure at moment of crack formation due to angle } \\
\text { rotation }\end{array}$} \\
\hline C5-1 B15 & 22.4 & & 48.1 & 46.0 & 105.9 & 88.3 \\
\hline
\end{tabular}




\begin{tabular}{|c|c|c|c|c|c|c|}
\hline C5-3 B15 & 21.6 & & 43.8 & & 70.6 & \\
\hline C6-1 B30 & 19.05 & \multirow{3}{*}{19.2} & \multicolumn{4}{|c|}{ Failure: crack in weld, $\mathrm{K}_{\mathrm{f}}=3.5-4.0 \mathrm{~mm}$} \\
\hline C6-2 B30 & 21.0 & & 25.5 & 280 & 41.8 & 272 \\
\hline C6-3 B30 & 17.7 & & 32.6 & 28.9 & 32.6 & 31.2 \\
\hline C7-1 B15 & 11.0 & \multirow{3}{*}{12.5} & 26.3 & \multirow{3}{*}{29.9} & 26.3 & \multirow{3}{*}{29.8} \\
\hline C7-2 B15 & 12.9 & & 32.1 & & 32.1 & \\
\hline C7-3 B15 & 13.6 & & 31.2 & & 31.2 & \\
\hline C8-1 B30 & 9.8 & \multirow{3}{*}{9.0} & 19.3 & \multirow{3}{*}{17.6} & 30.2 & \multirow{3}{*}{27.8} \\
\hline C8-2 B30 & 6.7 & & 17.8 & & 31.3 & \\
\hline C8-3 B30 & 10.6 & & 15.7 & & 22.1 & \\
\hline
\end{tabular}

The analysis of the results presented in Figures 4, 5, 6 and in Table 2 shows that:

- compliance ratios I 1 and their average value I1 av in the first practically linear part of the deformation before crack formation in the concrete is much less than the values of the compliance ratios I2 and I3 ( I2av and I3av );

- the largest average value of the compliance ratio I 1 av $=21.8 * 10-6 \mathrm{~mm} / \mathrm{H}$. It is obtained for the vertical L-shaped joints of C 5 series from the concrete of B15 class;

- the lowest average value of the compliance ratio I 1 av $=7.4 * 10-6 \mathrm{~mm} / \mathrm{N}$ is revealed for symmetrical joints of two blocks (series C3) using concrete of B30 class;

- the least variance in the values of the compliance ratios I 1 relative to the average value I 1 av was obtained from the test results of the vertical joints of series C5 $-\Delta 5=4.1 \%$; $\mathrm{C} 4-\Delta 4=5,3 \% ; \mathrm{C} 3-\Delta 3=6.8 \% ; \mathrm{C} 2-\Delta 2=7.4 \%$. The greatest variance in the values of the compliance ratios I 1 comparing with the value I 1 av obtained for a series of joints $\mathrm{C} 7-\Delta 7=20.8 \%$;

- full characteristic of the compliance I 2 (Figure 7), determined from the relative displacements at the maximum load, is characterized by the expectedly high and values of the compliance ratio. The spread of the compliance ratios relative to the average value of the results of three tests in each of the eight series does not exceed $20 \%$. The dependence of the decrease in the compliance ratio I $2 \mathrm{av}$ with increasing strength of the concrete is noted in all 3 types of the vertical joints;

- the largest average compliance ratio I $2 \mathrm{av}=46.6 * 10-6 \mathrm{~mm} / \mathrm{N}$ was observed for the $\mathrm{C} 5$ L-shaped joints of the concrete of B15 class;

- the lowest average compliance ratio I 2 av $=15.6 * 10-6 \mathrm{~mm} / \mathrm{N}$ was obtained for a series of the symmetrical joints of $\mathrm{C} 3$ panels of the concrete of B30 class.

\section{Conclusions}

1. The estimation of the compliance ratios of the mating elements of the vertical joints at three loading areas is given: before the crack formation in the concrete I 1; after the crack formation and up to the maximum load I 3; integral estimation I 2 - from the beginning of the loading to the maximum load.

2. The average value of the compliance ratio I 1 for the three samples on the linear area of the deformation of the vertical joint depends on the type of the joint and concrete class: the initial compliance ratio of the most rigid T-joint of 2 elements of the concrete of $\mathrm{B} 30$ class I $1 \mathrm{av}=7.4 * 10-6 \mathrm{~mm} / \mathrm{N} 3$ times less in comparison with the L-shaped joint of the concrete B15 panels.

3. For vertical joints of the panels of B15 class and B22.5 concrete, the use of the values of the compliance ratio I $1 \mathrm{av}$ (Table 2) in the calculations is possible at the load Ftr $\leq 50$ 
$\mathrm{kN}$ before the cracks in the concrete, and for the vertical joints of the panels of $\mathrm{B} 30$ class concrete under the loads $\mathrm{Ftr} \leq 100 \mathrm{kN}$.

4. Reducing full compliance characteristics I 2 av at increasing the concrete strength is observed in all 3 types of the vertical joints and is more pronounced as compared with the change of the compliance ratio I 1 av.

5. A large spread of the values of the compliance ratios I 3 to $50 \%$ for the joints of one series is determined, in particular, by different values of the crack formation (the beginning of the nonlinear deformation section). In this connection, the indicator I 3 can be used only as a qualitative assessment of the compliance of the vertical joints of the different designs in a nonlinear deformation section.

\section{References}

1. A.V. Granovskiy, A.I. Dottuev, PGS, 1, 17-20 (2014)

2. A.A. Karyakin, I.S. Derbentsev, P.V. Popp, Sci. search: mater. of the 3rd sci. conf. of post-graduate stud. and Ph.D, 1, 122-126 (2011)

3. I.S. Derbentsev, Sci. search: mater. of the 2 nd sci. conf. of post-graduate stud. and Ph.D, 1, 72-76 (2010)

4. D. Casagrande, G. Doudak, L. Mauro, A. Polastri, J. of Struct. Engineering, 144(2) (2018)

5. M. Chu, J. Liu, J. Hou, G. Qiu, G. Wang, J. of Build. Struct. 38(3), 84-92 (2017)

6. Y. Azumi, M. Murakami, J. of Struct. and Constr. Engineering 80(707), 93-103 (2015)

7. A.A. Karyakin, I.S. Derbentsev, M.V. Tarasov, IOP Conf. Series: Materials Sci. and Engineering, 262(1) (2017)

8. I. Derbentsev, A.A. Karyakin, A. Volodin, IOP Conf. Series: Materials Sci. and Engineering, 262(1) (2017)

9. J.P. Vella, R.L. Vollum, A. Jackson, Engineering Struct., 138, 351-366 (2017)

10. L. Raghavan, H. Thiagu, Int. J. of Civil Engineering and Technol., 8(4), 156-162 (2017)

11. A. Pustovgar, A.Tanasoglo, I. Garanzha, L. Shilova, A. Adamtsevich, MATEC Web of Conferences, 86, 04003 (2016)

12. Y. Kunin, A. Faizova, IOP Conf. Series: Materials Sci. and Engineering, 365 (2018)

13. A. Istomin, M. Medyankin, IOP Conf. Series: Materials Sci. and Engineering, 365 (2018) 